\title{
Intrathecal preservative-free normal saline challenge magnetic resonance myelography for the identification of cerebrospinal fluid leaks in spontaneous intracranial hypotension
}

\author{
Julius Griauzde, MD, ${ }^{1}$ Joseph J. Gemmete, MD, ${ }^{1-3}$ Aditya S. Pandey, MD, ${ }^{2}$ and \\ Neeraj Chaudhary, MD, MRCS, FRCR ${ }^{1,2}$ \\ Departments of ${ }^{1}$ Radiology, ${ }^{2}$ Neurosurgery, and ${ }^{3}$ Otolaryngology, University of Michigan Hospitals, Ann Arbor, Michigan
}

OBJECT A CSF leak can be difficult to locate in patients who present with spontaneous intracranial hypotension (SIH). The purpose of this case series was to describe the authors' experience with intrathecal preservative-free normal saline challenge coupled with contrast-enhanced MR myelography (CEMRM), which was used to provoke and detect a CSF leakage site in patients with $\mathrm{SIH}$.

METHODS The authors performed a retrospective review of the records of patients who underwent preservative-free normal saline challenge followed by intrathecal gadolinium (Gd) contrast infusion and MR myelography from 2010 to 2012.

RESULTS The records survey identified 5 patients who underwent 6 procedures. Intrathecal preservative-free normal saline challenge followed by CEMRM identified a CSF leak during 5 of the 6 procedures. Previous CT myelograms were available from 4 patients, which did not reveal a leakage site. A CT myelogram of 1 patient showed a single leak, but the authors' saline challenge-CEMRM technique identified multiple additional leakage sites. Three patients exhibited transient postprocedural symptoms related to the saline infusion, but no long-term or permanent adverse effects related to the procedure were observed.

CONCLUSIONS Instillation of preservative-free normal saline into the thecal sac followed by intrathecal Gd infusion is a safe technique that may increase the detection of a CSF leak on MR myelography images in patients with SIH.

http://thejns.org/doi/abs/10.3171/2014.12.JNS142057

KEY WORDS spontaneous intracranial CSF hypotension; magnetic resonance myelography; cerebrospinal fluid leak; spinal disorders; diagnostic and operative techniques

$\mathrm{S}$ PONTANEOUS intracranial hypotension (SIH) classically presents as a positional headache that is worsened by orthostasis. Additional symptoms may include dizziness, tinnitus, vomiting, altered mental status, and behavioral changes. ${ }^{10,11,16}$ Findings on routine brain CT and MRI scans help to confirm a clinical suspicion of SIH. ${ }^{5}$ These diagnostic imaging findings include pachymeningeal enhancement, a sagging brain, small ventricular size, and engorged venous sinuses. ${ }^{9}$ The combination of these clinical and imaging findings makes diagnosing an SIH of- ten straightforward. ${ }^{6}$ However, locating the causative CSF leak often remains a challenge. Although new therapeutic techniques have improved the rates of successful treatments of SIH patients with an occult leakage site, identifying the exact location of the CSF leak is preferred before deciding on therapy. ${ }^{11,15}$ The purpose of this case series was to present our experience with intrathecal preservative-free normal saline challenge followed by contrast-enhanced MR myelography (CEMRM), which we used to provoke and detect a CSF leak in patients with SIH.

ABBREVIATIONS CEMRM = contrast-enhanced MR myelography; $\mathrm{CTM}=\mathrm{CT}$ myelography; $\mathrm{Gd}$ = gadolinium; $\mathrm{SIH}$ = spontaneous intracranial hypotension . SUBMITTED September 5, 2014. ACCEPTED December 11, 2014.

INCLUDE WHEN CITING Published online July 3, 2015; DOI: 10.3171/2014.12.JNS142057.

DISCLOSURE The authors report no conflict of interest concerning the materials or methods used in this study or the findings specified in this paper. 


\section{Methods}

This study was approved by the institutional review board at the University of Michigan in Ann Arbor. We retrospectively reviewed cases of $\mathrm{SIH}$ at our institution in which preservative-free normal saline was instilled into the thecal sac followed by intrathecal gadolinium (Gd) contrast and total spine MRI in the period of 2010-2012. Pertinent medical records including procedural notes, laboratory values, and clinical data were reviewed. Outside images including those from CT, MRI, myelography, CT myelography (CTM), and CEMRM were reviewed and compared with the findings of intrathecal preservativefree normal saline challenge CEMRM by 2 board-certified neuroradiologists. Preprocedural and demographic patient data are summarized in Table 1.

\section{Patient Cohort}

Before presenting at our institution, the conditions of all patients had been extensively evaluated at major outside academic referral hospitals. The previous clinical and imaging findings suggestive of CSF hypotension identified a definitive anatomical location of a CSF leak in only 1 patient. To determine the anatomical location of the CSF leak with greater sensitivity and accuracy, we instilled preservative-free normal $(0.9 \% \mathrm{w} / \mathrm{v})$ saline into the thecal sac followed by infusion with intrathecal Gd contrast agent. Patients were informed of the potential risks of this procedure and that its full safety profile was unknown. $\mathrm{Pa}-$ tients were further informed of and consented to the offlabel use of intrathecal Gd.

\section{Procedure}

The patients were brought to the angiography suite and placed prone on the angiographic table. Conscious sedation was administered in all cases, except one in which general anesthesia was used because of the patient's altered mental status, as determined by the treating physician. Lidocaine was used to anesthetize the subcutaneous soft tissues. Under fluoroscopic guidance, a 20-gauge Tuohy needle or a 22-gauge spinal needle was advanced into the thecal sac in the lumbar spine below the level of the cauda equina. Correct needle placement was confirmed by return of clear CSF. When possible, an opening pressure was obtained. If there was no CSF return, a small amount of contrast agent was injected to confirm correct placement in the thecal sac. This was followed by a smallvolume injection $(>3 \mathrm{ml}$ ) of preservative-free normal saline to ensure free flow through the needle. An infusion pump was attached to the needle, and the preservative- free normal saline was instilled at a rate of $1 \mathrm{ml} / \mathrm{min}$ to a total volume of approximately one-third of the total CSF fluid volume. In 2 patients with marked intracranial hypotension and active intracranial pressure monitoring, additional preservative-free normal saline was infused.

After the saline infusion, $0.5 \mathrm{ml}$ of Magnevist (Bayer) or MultiHance (Bracco Diagnostics) contrast agent in approximately $10 \mathrm{ml}$ of preservative-free normal saline was bolused into the thecal sac. We considered administering approximately $70 \mathrm{ml}$ of saline as safe given that this volume equals approximately one-third of the CSF volume (the average normal CSF volume is $140-270 \mathrm{ml}) .{ }^{1}$ The average total volume of saline infused was $75.8 \mathrm{ml}$ (range $55.5-120 \mathrm{ml}$ ). After the injection, the needle was removed and hemostasis was obtained. The patient was placed in reverse Trendelenburg position for 5 minutes to allow progression of the contrast agent to the skull base. The patient was then also placed in the left lateral decubitus, right lateral decubitus, supine, and prone positions for 5-10 minutes before imaging. Two hours after the injection, with the patient in a supine position, a thin-section, total spine MRI scan was taken according to the following protocol: fat-saturated T1-weighted images were taken in 3 orthogonal planes in the cervical, thoracic, and lumbar spine. Coronal and sagittal T1-weighted images (with 500-msec TR and 17-msec TE; 2 signals were acquired) and axial T1-weighted images (with 600-msec TR and 17-msec TE; 2 signals were acquired) were obtained using a 1.5-T MR unit (GE HealthCare). None of the patients had a history of skull base surgery, rhinorrhea, or otorrhea; therefore, imaging of the skull base was not performed. Patients who had significant medical comorbidities or complex neurological symptoms were monitored overnight.

\section{Results}

Our records review identified 5 patients ( 3 women and 2 men) who had undergone 6 procedures. The average age of the patients was 34.8 years (range 22-53 years) (Table 1). All of the patients presented with positional headache as one of their symptoms. One patient also presented with severe cognitive decline and behavioral changes. None of the patients had a history of a connective tissue disorder.

Preprocedural imaging from outside hospitals was available for all 5 patients, including myelography and CTM images. A CSF leakage site was diagnosed on CEMRM images as a focused accumulation of contrast agent outside the thecal sac (Fig. 1). After the infusion of preservative-free normal saline and the Gd contrast agent, we identified a leakage site in 5 of 6 cases (83\%) (Fig. 2).

TABLE 1. Characteristics of the cases in this study

\begin{tabular}{cclc}
\hline Case No. & Age (yrs), Sex & \multicolumn{1}{c}{ Symptoms } & Previous Myelography Results \\
\hline 1 & $30, \mathrm{M}$ & Orthostatic headache, neck stiffness, \& nausea & No leak identified w/ CTM \\
\hline 2 & $32, \mathrm{~F}$ & Orthostatic headache & No leak identified w/ CTM \\
\hline 3 & $37, \mathrm{~F}$ & Orthostatic headache & Leak identified It T11-12 w/ CTM \\
\hline 4 & $53, \mathrm{M}$ & $\begin{array}{c}\text { Orthostatic headache, behavioral changes, \& altered mental } \\
\text { status }\end{array}$ & No leak identified w/ CTM \\
\hline 5 & $22, \mathrm{~F}$ & Orthostatic headache, nausea, \& vomiting & No leak identified w/ CTM \\
\hline
\end{tabular}



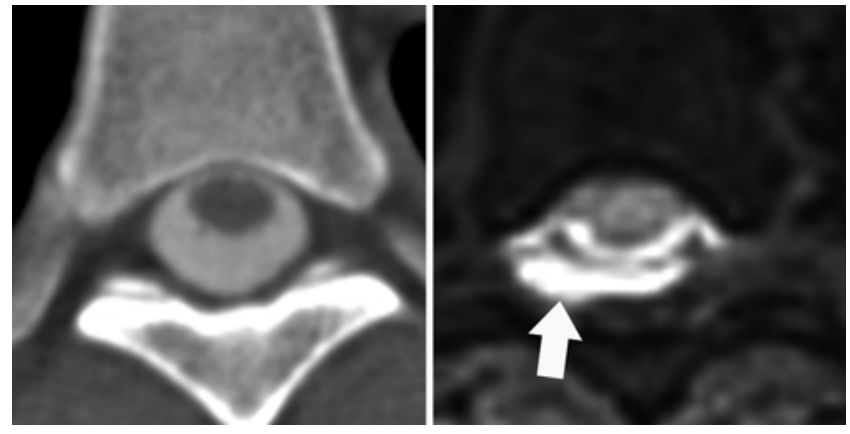

FIG. 1. CEMRM results for Case 1 in Table 1, a 30-year-old man who presented with an orthostatic headache, neck stiffness, and nausea. Left: A previous axial CT myelogram at the midthoracic level shows no evidence of a CSF leak. Right: Axial fat-saturation T1weighted MR image at the midthoracic level (the same region as in the left image) after intrathecal infusion of preservative-free normal saline followed by infusion with MultiHance shows the contrast agent outside of the thecal sac (indicated by white arrow).

Four of the patients had undergone previous myelography and CTM that did not locate a leakage site, and in 1 case, a single leakage site had been identified. In that case, multiple additional leakage sites were identified with our procedure. Opening pressure was recorded in 5 of the 6 procedures.

The procedural and postprocedural data are summarized in Table 2. Three patients immediately noted symptoms after the procedure, which included shortness of breath, anxiety, pelvic pressure, a headache that was different from the presenting headache, and numbness or tingling in both upper and lower extremities. These symptoms were transient and resolved within a few hours of the procedure, and a neurological examination noted no objective changes. Three patients reported transient resolution of their headache, and no long-term adverse effects related to the procedure were observed. All 5 patients with a CSF leak underwent a large-volume epidural blood patch procedure through a single-catheter access site to multiple sites in the epidural space, as described previously. ${ }^{11}$ Four patients exhibited improvement of their symptoms with this procedure. One of these patients pursued experimental treatment at another institution despite the improving symptoms. One patient's symptoms also initially improved but reverted back to baseline.

\section{Discussion}

CTM has generally been considered as the diagnostic test of choice for identifying a CSF leakage site in SIH. ${ }^{18}$ Adjunctive techniques have been developed in an attempt to improve the sensitivity of detecting a CSF leak. Dynamic CTM provides increased temporal and spatial resolutions, which improve leak identification in cases of high-flow leakage. ${ }^{14}$ Similarly, CEMRM appears to be more sensitive than conventional CTM, enabling improved identification of subtle CSF leaks.,.$^{2,8,19}$ However, even CEMRM does not identify a significant proportion (that is, 63\%-79\%) of CSF leakage sites. ${ }^{2,8}$ The possible causes for this shortcoming include transient CSF leakage, which may therefore not occur during the scanning inter-
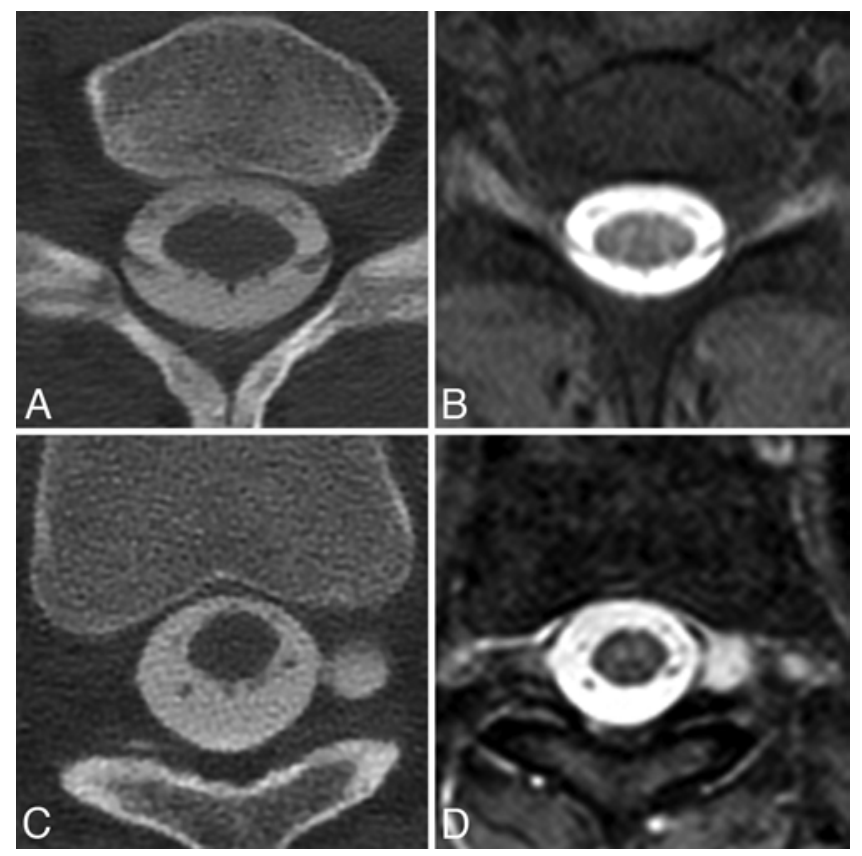

FIG. 2. CEMRM results for Case 5 in Table 1, a 22-year-old woman who presented with disabling orthostatic headache, nausea, and vomiting. A: A previous axial CT myelogram of the lower cervical spine shows no evidence of a CSF leak. B: Axial fat-saturation T1-weighted MR image at the same level as shown in $A$ after intrathecal infusion of preservative-free normal saline shows MultiHance contrast agent extending outside the nerve root sleeves. C: Axial CT myelogram at the level of T-11 shows a nerve root sleeve cyst. D: Axial fat-saturation T1weighted MR image at the same level as shown in $\mathrm{C}$ shows MultiHance contrast agent that extends lateral to the nerve root sleeve cyst.

val during imaging, very small leaks that are below the resolution threshold of current imaging techniques, and very-low-pressure CSF leaks resulting from markedly low intrathecal pressure.

To overcome these shortcomings, we aimed to artificially increase the intrathecal pressure by infusing preservative-free normal saline into the thecal sac. Intrathecal infusion of preservative-free normal saline has been previously reported as a safe and possibly life-saving therapy in severe cases of SIH. ${ }^{3,7,17}$ Increasing the pressure in the thecal sac should increase the propensity for CSF to leak across a dural tear and improve visualization of the leak after administration of intrathecal Gd. In keeping with this hypothesis, we were able to detect a CSF leak in 5 of 6 infusion procedures. In 4 cases, a leakage site had not been identified on previous CTM images from outside institutions, and in 1 case, we identified multiple additional leakage sites not detected with a previous CTM.

The overall safety profile of the reported technique is unknown. Previous studies have not reported any procedure-related complications with intrathecal saline infusion. ${ }^{37,17}$ The authors in these earlier reports used infusion rates ranging from 0.17 to $0.50 \mathrm{ml}$ per minute. We infused at a higher rate of $1 \mathrm{ml}$ per minute and did not observe any long-term or permanent adverse effects related to our procedure. Three patients did experience immediate transient symptoms, which included feelings of anxiety, shortness of breath, pelvic pressure, headache, and numbness 
TABLE 2. Procedural and postprocedural data of the 5 cases in this study*

\begin{tabular}{|c|c|c|c|c|c|}
\hline $\begin{array}{l}\text { Case } \\
\text { No. }\end{array}$ & $\begin{array}{l}\text { Vol of IPFNS } \\
\text { Injected (ml) }\end{array}$ & $\begin{array}{c}\text { Contrast Agent Type, } \\
\text { Vol (ml) }\end{array}$ & $\begin{array}{c}\text { CSF Leakage Site Identified } \\
\text { \& Location }\end{array}$ & $\begin{array}{l}\text { Transient Adverse Effects } \\
\text { Immediately Postprocedure }\end{array}$ & Opening CSF Pressure \\
\hline 1 & 60 & MultiHance, 0.5 & Yes, at T5-10 & None & $2 \mathrm{~mm} \mathrm{H}_{2} \mathrm{O}$ \\
\hline 2 & 55.5 & MultiHance, 0.5 & No & Pelvic \& lower extremity pain & $-4 \mathrm{~mm} \mathrm{Hg}$ (ICP monitor) \\
\hline 3 & 79.5 & MultiHance, 0.5 & $\begin{array}{l}\text { Yes, multiple sites at the lower cervical \& } \\
\text { thoracic spine }\end{array}$ & $\begin{array}{l}\text { Numbness in arms \& legs, SOB, } \\
\text { \& anxiety }\end{array}$ & $0 \mathrm{~mm} \mathrm{H}_{2} \mathrm{O}$ \\
\hline $4 \dagger$ & $120 \& 70$ & $\begin{array}{l}\text { Magnevist, } 0.5 \& \\
\text { MultiHance, } 0.5\end{array}$ & $\begin{array}{l}\text { Yes, multiple sites at the middle \& lower } \\
\text { thoracic spine }\end{array}$ & Mild headache & $-12 \mathrm{~mm} \mathrm{Hg}$ (ICP monitor) \\
\hline 5 & 70 & MultiHance, 0.5 & Yes, T3-7 \& T12-L1 & None & $4 \mathrm{~mm} \mathrm{H}_{2} \mathrm{O}$ \\
\hline
\end{tabular}

ICP = intracranial pressure; IPFNS = intrathecal preservative-free normal saline; SOB = shortness of breath.

* None of the patients in these cases reported any permanent or long-term adverse effects associated with the saline challenge-CEMRM procedure.

$\dagger$ In this case, 2 separate procedures were performed, and saline and contrast agent volumes are indicated for each procedure.

and tingling in both upper and lower extremities. Three patients also noted transient resolution of their headache. These symptoms were not accompanied by any objective changes in a neurological examination and none persisted beyond the day of the procedure. The briefness of the observed symptoms is probably attributable to rapid normalization of the patient's intracranial pressure.

We suggest that slower infusion rates would result in fewer of the aforementioned symptoms, but slower infusion may also prevent sufficient pressure to build up within the thecal sac to create a CSF leak. Theoretically, overinfusion (by rate or total volume) could lead to more severe sequelae of intracranial hypertension. Because of this risk, we note that close neurological monitoring is needed during and immediately after the procedure. In patients who do show new symptom onset, close neurological monitoring should continue until any of these new symptoms resolve. Furthermore, intracranial pressure monitoring may be indicated in patients with severe symptoms of SIH, in those with multiple medical or neurological comorbidities, and in those receiving large-volume intrathecal infusions. An additional previously suggested risk is the possibility that the intrathecal infusion enlarges an already present dural tear. ${ }^{3}$ Although this is certainly possible, such occurrence may actually improve visualization of the CSF leak allowing for more rapid and targeted therapy at the site of the tear.

Consideration must also be given to the risk profile of administering intrathecal Gd. Intrathecal Gd is generally safe at low volumes ranging from 0.5 to $1.0 \mathrm{ml} .^{12,19}$ Our experience with an infusion volume of $0.5 \mathrm{ml}$ in each case supports this earlier observation. However, intrathecal use of Gd remains off label, and severe adverse effects have been reported at higher doses of this contrast agent. ${ }^{13} \mathrm{~Pa}-$ tients must therefore be made aware of all possible adverse effects associated with use of this agent, and appropriate consent to off-label use of $\mathrm{Gd}$ must be obtained. ${ }^{4}$

Our investigation was limited by a small cohort size and its retrospective nature. Future studies should include larger patient populations and should also directly compare the efficacy and safety of normal saline challenge CEMRM with conventional CEMRM and with CTM. In addition, to obviate the need for intrathecal administration of the Gd contrast agent, CTM after intrathecal normal saline challenge could be attempted.

\section{Conclusions}

Our experience with preservative-free normal saline challenge combined with CEMRM imaging demonstrates that it is a relatively safe procedure and may aid in improved detection of CSF leaks in patients with SIH.

\section{References}

1. Agamanolis DP: Cerebrospinal fluid. Neuropathology: An illustrated interactive course for medical students and residents. (http://neuropathology-web.org/chapter14/chapter 14CSF.html) [Accessed April 28, 2015]

2. Akbar JJ, Luetmer PH, Schwartz KM, Hunt CH, Diehn FE, Eckel LJ: The role of MR myelography with intrathecal gadolinium in localization of spinal CSF leaks in patients with spontaneous intracranial hypotension. AJNR Am J Neuroradiol 33:535-540, 2012

3. Akkawi N, Locatelli P, Borroni B, Agosti C, Pezzini A, Stefini R, et al: A complicated case of intracranial hypotension: diagnostic and management strategies. Neurol Sci 27:63-66, 2006

4. Albayram S, Kilic F, Ozer H, Baghaki S, Kocer N, Islak C: Gadolinium-enhanced MR cisternography to evaluate dural leaks in intracranial hypotension syndrome. AJNR Am J Neuroradiol 29:116-121, 2008

5. Albayram S, Ozer H, Kara B: Diagnostic criteria for spontaneous spinal CSF leaks and intracranial hypotension. AJNR Am J Neuroradiol 29:e94, e85, 2008 (Letter)

6. Albayram S, Ulu MO, Isler C: Intracranial hypotension. J Neurosurg 109:362, 2008 (Letter)

7. Binder DK, Dillon WP, Fishman RA, Schmidt MH: Intrathecal saline infusion in the treatment of obtundation associated with spontaneous intracranial hypotension: technical case report. Neurosurgery 51:830-837, 2002

8. Chazen JL, Talbott JF, Lantos JE, Dillon WP: MR myelography for identification of spinal CSF leak in spontaneous intracranial hypotension. AJNR Am J Neuroradiol 35:2007-2012, 2014

9. Christoforidis GA, Mehta BA, Landi JL, Czarnecki EJ, Piaskowski RA: Spontaneous intracranial hypotension: report of four cases and review of the literature. Neuroradiology 40:636-643, 1998

10. Chung SJ, Kim JS, Lee MC: Syndrome of cerebral spinal fluid hypovolemia: clinical and imaging features and outcome. Neurology 55:1321-1327, 2000

11. Griauzde J, Gemmete JJ, Chaudhary N, Wilson TJ, Pandey AS: Large-volume blood patch to multiple sites in the epidural space through a single-catheter access site for treatment of spontaneous intracranial hypotension. AJNR Am J Neuroradiol 35:1841-1846, 2014 
12. Jinkins JR, Rudwan M, Krumina G, Tali ET: Intrathecal gadolinium-enhanced MR cisternography in the evaluation of clinically suspected cerebrospinal fluid rhinorrhea in humans: early experience. Radiology 222:555-559, 2002

13. Kapoor R, Liu J, Devasenapathy A, Gordin V: Gadolinium encephalopathy after intrathecal gadolinium injection. Pain Physician 13:E321-E326, 2010

14. Luetmer PH, Mokri B: Dynamic CT myelography: a technique for localizing high-flow spinal cerebrospinal fluid leaks. AJNR Am J Neuroradiol 24:1711-1714, 2003

15. Ohtonari T, Ota S, Nishihara N, Ota T, Tanaka Y, Sekihara Y, et al: A novel technique of multiple-site epidural blood patch administration for the treatment of cerebrospinal fluid hypovolemia. J Neurosurg 116:1049-1053, 2012

16. Paldino M, Mogilner AY, Tenner MS: Intracranial hypotension syndrome: a comprehensive review. Neurosurg Focus 15(6):ECP2, 2003

17. Sass C, Kosinski C, Schmidt P, Mull M, Schulz J, Schiefer J: Intrathecal saline infusion: an emergency procedure in a patient with spontaneous intracranial hypotension. Neurocrit Care 19:116-118, 2013

18. Schievink WI, Meyer FB, Atkinson JL, Mokri B: Spontaneous spinal cerebrospinal fluid leaks and intracranial hypotension. J Neurosurg 84:598-605, 1996
19. Tali ET, Ercan N, Krumina G, Rudwan M, Mironov A, Zeng QY, et al: Intrathecal gadolinium (gadopentetate dimeglumine) enhanced magnetic resonance myelography and cisternography: results of a multicenter study. Invest Radiol 37:152-159, 2002

\section{Author Contributions}

Conception and design: Gemmete, Griauzde. Acquisition of data: Gemmete, Griauzde. Analysis and interpretation of data: Gemmete, Griauzde. Drafting the article: all authors. Critically revising the article: all authors. Reviewed submitted version of manuscript: all authors. Approved the final version of the manuscript on behalf of all authors: Gemmete. Statistical analysis: Gemmete. Administrative/technical/material support: Gemmete. Study supervision: Gemmete.

\section{Correspondence}

Joseph J. Gemmete, Departments of Radiology, Neurosurgery, and Otolaryngology, University of Michigan Hospitals, UH B1D 328, 1500 E. Medical Center Dr., Ann Arbor, MI 48109. email: gemmete@med.umich.edu. 